\title{
Drug vs Class-Specific Black Box Warnings: Does One Bad Drug Spoil the Bunch?
}

\author{
Stacie B. Dusetzina, $P h D^{7}$ and G. Caleb Alexander, MD, $M S^{2,3,4}$ \\ 'Department of Health Care Policy, Harvard Medical School, Boston, MA, USA; '2Department of Medicine, University of Chicago Hospitals, \\ Chicago, IL, USA; ${ }^{3}$ Center for Health and the Social Sciences, University of Chicago, Chicago, IL, USA; ${ }^{4}$ Department of Pharmacy Practice, \\ University of Illinois at Chicago School of Pharmacy, Chicago, IL, USA.
}

$\mathrm{J}$ Gen Intern Med 26(6):570-2

DOI: $10.1007 / \mathrm{s} 11606-011-1714-9$

( ) Society of General Internal Medicine 2011

$\mathrm{S}$ ince safety concerns regarding prescription drugs are often discovered only after a medicine has been approved and released on the market, FDA regulatory advisories serve as an important means of communicating risk information to providers and to the general public. Although there are a variety of methods that the FDA uses to communicate such information, black box warnings are reserved for those deemed of highest public health importance. In many cases, risk information may be available for only select drugs within a therapeutic class, and thus the Agency often has to decide how broadly an advisory should be applied when faced with incomplete information. Should a warning derived from data about a single agent be similarly applied across drugs within the same chemical class or across agents with similar pharmacologic effects? Why or why not? What factors should guide this decision?

As with many decisions that the Agency makes, this deliberation can be complex, since it requires the combination of facts and judgments in the setting of incomplete scientific information. To complicate matters further, advisories focused on a single agent may have substantially different effects than advisories focused on an entire therapeutic class. For example, applying an advisory to a single member of a class may erroneously suggest superior safety of other members of the class in the absence of evidence to the contrary, and may also erode a particular agent's market share and thus be met with resistance by industry stakeholders. The lack of specificity of a class-wide warning may blunt the impact of an advisory. ${ }^{1}$ Too many advisories may lead to "alert fatigue." Poorly worded or framed advisories may increase their spillover to untargeted populations. Indeed, as the history of risk communication has shown us, poorly managed messages about risks can become risks themselves. ${ }^{2,3}$

In this issue of JGIM, Panagiotou et al. assess the application of black box warnings across drugs within the same chemical classes. ${ }^{4}$ The authors identified 20 top-selling drugs (index drugs) representing 20 chemical classes in 2008, selecting 10 medicines with a black box warning and 10 medicines without one. They then searched the labels for each drug in the defined classes, including those members that had been withdrawn from the market, and quantified the extent to

Published online April 7, 2011 which these labels reflected similar warning information as the label of the index drug.

These 20 classes yielded 176 therapies for which the authors could obtain FDA labels. Among these classes, the authors identified seven therapies that had been withdrawn from the market for safety reasons, but with little overlap between black box warning information on these agents and available sameclass agents. For example, while troglitazone was withdrawn from the market because of its hepatotoxicity, no other glitazone label examined had a similar black box label for this toxicity. Among the drug labels reviewed, the authors identified 15 drugs for which black box warnings were not applied equally across other members of the class. The authors indicate that 10 of these 15 warnings were included in some form on the other agents within the class, but 5 warnings were completely excluded from same-class agents. The authors concluded that differences in labeling within a treatment class may shape impressions about drug safety and that more systematic labeling is needed.

The authors examine an important topic-how systematically the FDA regulatory advisories are applied across agents within a chemical class-and their analysis provides an opportunity to consider a variety of factors that the Agency must consider when issuing such advisories. Their first conclusion, that differences in labeling may shape perceptions of safety, is unobjectionable. However, their second conclusion, that more systematic labeling is needed, raises a much more complicated set of issues. This is because it requires a consideration of the specific clinical circumstances of each advisory, and these examples demonstrate the complicated nature of applying black box warning information across chemical classes. Table 1 describes three of the five settings where the authors indicate that black box warning information on one or more drugs within a chemical class was absent from other agents within that class. We use these three cases to highlight the importance of considering the clinical context when applying black box warnings to agents within the same chemical class.

\section{EXAMPLE 1: ADVISORY DEVOTED TO SPECIFIC CLINICAL INDICATION}

An advisory regarding increased risk of suicidality among children and adolescents taking antidepressants for major depression and other psychiatric disorders was issued for quetiapine, but not for the broader class of 5HT2-D2 antagonists. It is important to note that this warning was related to a 
Table 1. Contrasting Clinical Evidence in Three Settings Where an FDA Advisory Was Issued

\begin{tabular}{|c|c|c|c|}
\hline $\begin{array}{l}\text { Medication } \\
\text { subject to black } \\
\text { box warning }\end{array}$ & Safety concern & Therapeutic class & Considerations \\
\hline $\begin{array}{l}\text { Quetiapine } \\
\text { (Seroquel) }\end{array}$ & $\begin{array}{l}\text { Suicidal thinking and behavior } \\
\text { among children, adolescents, and } \\
\text { young adults using drug for } \\
\text { depressive disorders }\end{array}$ & 5HT2-D2 antagonists & $\begin{array}{l}\text { - Quetiapine only member of broader therapeutic class } \\
\text { with labeled indication for bipolar depression (Seroquel } \\
\text { and Seroquel XR) or use with antidepressants as an } \\
\text { adjunctive treatment of major depressive disorder }\end{array}$ \\
\hline $\begin{array}{l}\text { Olanzapine } \\
\text { (Zyprexa } \\
\text { Relprevv) }\end{array}$ & $\begin{array}{l}\text { Post-injection delirium and/or } \\
\text { sedation }\end{array}$ & $\begin{array}{l}\text { Intramuscular } 5 \mathrm{HT} 2-\mathrm{D} 2 \\
\text { antagonists with prolonged } \\
\text { half-life }\end{array}$ & $\begin{array}{l}\text { - Olanzapine (Zyprexa Relprevv) label indicates } 2 \% \text { of } \\
\text { patients in pre-marketing studies experienced this } \\
\text { adverse event } \\
\text { - Label for other injectable 5HT2-D2 antagonists } \\
\text { (Risperdal Consta and Invega Sustenna) contains details } \\
\text { of pre-marketing evidence indicating no relationship to } \\
\text { post-injection delirium/sedation syndrome }\end{array}$ \\
\hline Troglitazone & Hepatotoxicity & Glitazones & $\begin{array}{l}\text { - Despite similar chemical structure, substantial } \\
\text { heterogeneity in likelihood of hepatotoxicity between } \\
\text { troglitazone, rosiglitazone, and pioglitazone" } \\
\text { - Label for other glitazones identifies potential for } \\
\text { hepatotoxicity }\end{array}$ \\
\hline
\end{tabular}

specific risk related to antidepressant use, not specifically to 5HT2-D2 antagonist use. However, among the 5HT2-D2 antagonists, only quetiapine had an approved indication for use as an adjunctive treatment to antidepressants for major depressive disorder. Although other 5HT2-D2 antagonists may be used in combination with antidepressants, the lack of approval for their use with antidepressants (the true target of this warning) may have been the basis for the exclusion of this warning from other 5HT2-D2 drug labels.

\section{EXAMPLE 2: ADVISORY BASED ON PRE-MARKETING ADVERSE EVENTS}

Among 5HT2-D2 antagonists a warning related to post-injection delirium and/or sedation was applied to olanzapine, but not to the two other agents within this same chemical class, risperidone or paliperidone. This warning appears to have resulted from premarketing evidence for olanzapine, where $2 \%$ of patients experienced this adverse effect. ${ }^{5}$ Importantly, there was no evidence at the time of the advisory suggesting a classwide effect, and indeed, evidence gathered since suggests that this adverse effect is specific to olanzapine alone. ${ }^{6}$ Thus, it isn't clear that labeling regarding the potential risks in question should have occurred differently than the actions undertaken by the Agency.

\section{EXAMPLE 3: ADVISORY ON WITHDRAWN PRODUCT NOT APPLIED TO MARKETED PRODUCTS}

Neither pioglitazone (Actos) nor rosiglitazone (Avandia) contains the boxed warning that troglitazone carried prior to its removal from the market. Yet neither are currently believed to carry the same risk. ${ }^{7}$ Further, both drug labels mention "liver enzyme monitoring" and contain information related to "hepatic effects" in the warnings or precautions sections. Given the lack of evidence for hepatotoxicity for these agents and recommendations made on the current labels, it seems that a black box warning would not be warranted in this case.
Safety concerns regarding the cardiovascular risks of the glitazones offer another window through which to consider drug- vs. class-specific regulatory advisories. Some early signals suggested that the cardiovascular risks of glitazones were class-wide, ${ }^{8}$ while subsequent evidence suggested that these effects varied by drug, ${ }^{9-11}$ and the best current available evidence suggests considerably greater risk of rosiglitazone than pioglitazone. ${ }^{7,12,13}$ Based on accumulating evidence, in May 2007 the Food and Drug Administration (FDA) issued an advisory about rosiglitazone ${ }^{14}$ followed in August 2007 by one for all glitazones, ${ }^{15}$ followed by several advisories and regulatory actions since. What was the effect of these advisories and accumulating scientific evidence? The initial rosiglitazone advisory was associated with substantial overall decreases in its utilization, ${ }^{16}$ albeit with a non-uniform response across different geographical areas of the country. ${ }^{17}$ An initial classwide advisory or less discrimination by the agency regarding differences in safety among the glitazones may have led to substantially different and less well-informed choices by patients and providers. Thus, although the FDA has been criticized for not acting sooner or more forcefully to limit potential harm from rosliglitazone, ${ }^{18}$ it is not clear that a blanket advisory in 2007 for all glitazones that failed to emphasize the greater concern regarding roslitazone than pioglitazone would have been appropriate. In fact, evidence at that time and since suggest otherwise.

\section{LOOKING FORWARD}

At the time that a safety concern arises regarding a prescription drug, the FDA is responsible for weighing available evidence and assessing the risks and benefits of issuing an advisory on the targeted patient population, as well as considering potential impacts of the advisory on non-targeted populations. They must consider the level of available evidence for either drug or class-level warnings, the magnitude of potential harm associated with the use of the drug, and a variety of other factors, such as potential unintended consequences from an advisory. Certainly the Agency should strive for as 
systematic a process as possible, but whether or not advisories should be uniformly applied classwide can only be judged in the contexts of specific clinical settings. Regrettably, all too often, these contexts reveal differences in evidence, pharmacokinetics, or a variety of relevant contextual factors that justify departure from a one-size-fits-all, or classwide, approach.

Funding: This work was supported by the Agency for Healthcare Research and Quality (RO1 HSO189960) and the National Institutes of Mental Health (T32 MH019733-17). The funding sources had no role in the design and conduct of the study; collection, management, analysis, or interpretation of the data; and preparation, review, or approval of the manuscript for publication.

Corresponding Author: Stacie B. Dusetzina, $\mathrm{PhD}$, Department of Health Care Policy, Harvard Medical School, 180 Longwood Avenue, Boston, MA 02115, USA (e-mail: Dusetzina@hcp.med.harvard.edu).

\section{REFERENCES}

1. Goldman SA. Communication of medical product risk: how effective is effective enough? Drug Saf. 2004;27:519-34.

2. Furedi A. The public health implications of the 1995 "pill scare". Hum Reprod Update. 1999;5:621-6.

3. Bahri P. Public pharmacovigilence communication: a process calling for evidence-based, objective-driven strategies. Drug Saf. 2010;33:1065-79.

4. Panagiotou OA, Contopoulos-Ioannidis DG, Papanikolaou PN, Ntzani EE, Ioannidis JPA. Different black box warning labeling for same-class drugs. JGIM. 2011

5. Food and Drug Administration. Available at: http://www.accessdata.fda. gov/drugsatfda_docs/label/2010/022173s009lbl.pdf (Accessed March 16, 2011).

6. Alphs L, Gopal S, Karcher K, et al. Are the long-acting intramuscular formulations of risperidone or paliperidone palmitate associated with post-injection delirium/sedation syndrome? An assessment of safety databases. Curr Drug Saf. 2011;6:43-5.

7. Tolman KG. The safety of thiazolidinediones. Expert Opin Drug Saf. 2011 Mar 3. Available at: http://informahealthcare.com/doi/abs/ 10.1517/14740338.2011.534982 (Accessed March 8, 2011).

8. Wooltorton E. Rosiglitazone (avandia) and pioglitazone (actos) and heart failure. CMAJ. 2002;166:219.

9. Nissen SE, Wolski K. Effect of rosiglitazone on the risk of myocardial infarction and death from cerebrovascular disease. N Engl J Med. 2007;356:2457-71

10. Goldberg RB, Kendall DM, Deeg MA, et al. A comparison of lipid and glycemic effects of pioglitazone and rosiglitazone in patients with type 2 diabetes and dyslipidemia. Diabetes Care. 2005;28:1547-54.

11. Dormandy JA, Charbonnel B, Eckland DJ, et al. Secondary prevention of macrovascular events in patients with type 2 diabetes in the PROactive Study (PROspective pioglitAzone Clinical Trial In macroVascular Events): a randomised controlled trial. Lancet. 2005; 366:1279-89

12. Hernandez AV, Usmani A, Rajamanickam A, Moheet A. Thiazolidinediones and risk of heart failure in patients with or at high risk of type 2 diabetes mellitus: a meta-analysis and meta-regression analysis of placebo-controlled randomized clinical trials. Am J Cardiovasc Drugs. 2011 Feb 3.

13. Simo R, Rodriguez A, Caveda E. Different effects of thiazolidinediones on cardiovascular risk in patients with type 2 diabetes mellitus: pioglitazone versus rosiglitazone. Curr Drug Saf. 2010;5:234-44.

14. Food and Drug Administration. Available at: http://www.fda.gov/Safety/ MedWatch/SafetyInformation/SafetyAlertsforHumanMedicalProducts/ ucm150831.htm (Accessed March 16, 2011)

15. Food and Drug Administration. Available at: http://www.fda.gov/Safety/ MedWatch/SafetyInformation/SafetyAlertsforHumanMedicalProducts / ucm150825.htm (Accessed March 16, 2011).

16. Cohen A, Rabbani A, Shah N, Alexander GC. Changes in glitazone use among office-based physicians in the United States, 2003-2009. Diabetes Care. 2010;33:823-5.

17. Shah ND, Montori VM, Krumholz HM, Tu K, Alexander GC, Jackevicius CA. Geographic variation in the response to FDA boxed warnings for rosiglitazone. N Engl J Med. 2010;22:2081-4.

18. Cohen D. Insiders criticise FDA's decision not to withdraw rosiglitazone. BMJ. 2010;341:c5333. 